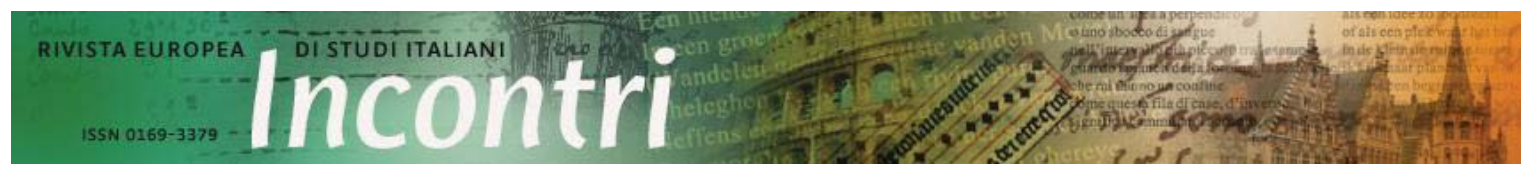

URN:NBN:NL:Ul:10-1-114269 - Publisher: Igitur publishing

Content is licensed under a Creative Commons Attribution 3.0 License

Anno 28, 2013 / Fascicolo 2 - Website: www.rivista-incontri.nl

\title{
Editorial - Editoriale Politics and Culture in the Italian Middle Ages
}

\section{David Napolitano}

In this thematic issue, the editorial board of Incontri wishes to highlight the Italian Middle Ages, a fascinating time when kings, emperors and popes vied for control over different parts of the Italian peninsula, while autonomous city-republics emerged, triumphed and disappeared.

This thematic issue will examine the legitimization of medieval power through the production and use of culture, in its different forms of expression. Throughout the Italian Middle Ages rulers have appealed to a wide range of cultural instruments in order to legitimize their authority. To further political goals, chronicles were filled with heroic deeds, and political theories were eagerly spun to promote particular forms of rule. Artists were also employed to visually support the legitimacy of particular claims on an area or to underline the illustrious and noble character of a lineage. Imposing buildings were erected to indicate centres of power, and public places offered convenient platforms for politically motivated rituals and spectacles.

This issue's eight contributions cover a period of five hundred years (1050-1550) and a wide range of literary, historical, art historical and archaeological perspectives. It provides a platform for a selected mixture of scholars - from the Czech Republic, Italy, the United Kingdom, and the United States - to present their most recent research on this topic. These scholars represent a wide spectrum of academic experience, from the starting Ph.D candidate to the seasoned lecturer.

The contributions have been arranged chronologically based upon the subject, starting with a case study by Cristiano Mengarelli that explores the Bishop of Anagni, Pietro da Salerno (d. 1105), a key figure in the history of this city located in the hills southeast of Rome. Building upon his collected studies on this city and figure, and his experience as an archaeological expert, Mengarelli provides an overview of the different actions undertaken by this bishop, effectively resulting in the urban renewal of an entire city district, and demonstrates the importance of this material legacy as an instrument of political legitimacy.

In her contribution on the well-known chronicle by Salimbene de Adam (1221c.1288), Marina Nardone examines Salimbene's political agenda, building upon an interesting interpretation of the epilogue of Salimbene's rendition of the Battle of Cortenuova (1237), which confronts his account with what is known about the underlying historical reality. Moreover, she posits the resulting insight in Salimbene's agenda as an 
illustration of a need to consider proper historical contextualisation when using medieval quotations in modern studies.

David Napolitano focuses on the corpus of texts which he examines as part of his Ph.D research: a series of political advice books written for Italian city magistrates, known as the podestà literature (1220s-1260s). Conscious that the existence of a particular label to denominate a particular group of texts colours the focus of the scholarly community, that it generates the attention of scholars particularly interested in a specific topic, and that it steers their reading of the content of these texts, he argues that the continued use of a specific podesta label for this type of works is still justified and warranted, which is a position that runs counter to a recent appeal to position these texts under the general umbrella of didactic-rhetorical literature.

In his contribution, Luca Demontis provides us with another case study, this time on Raimondo della Torre (1273-1299), Patriarch of Aquileia. Building upon his earlier work on the della Torre family, he shows that this patriarch consciously used ecclesiastic and civil ceremonies, architectonic projects, and coin minting to promote his princedom.

Next, Matteo Bosisio situates the Ecerinis by Albertino Mussato (1261-1329), the first tragedy in European literature, within the historical and cultural context of Padua at the turn of the thirteenth century. Based upon a detailed analysis of the choruses in this play he argues that this work on the catastrophic rule of Ezzelino III da Romano (1237-1259) over Padua served to contemporaries of Mussato as an example of - and warning against - the expansionism of Cangrande della Scala (1291-1329).

Sharing with us the fruits of a larger project on the works of Petrarch, funded by the Czech Science Foundation, the contribution by Jiří Špička aims to demonstrate that Petrarch (1304-1374) was not only an outstanding poet and scholar of his age, but also an interesting example of a public intellectual ante litteram.

Michele Campopiano presents us with one of the results of another collaborative research project, this time funded by the French Science Foundation and centred on the function of the myth of Alexander the Great in European medieval literature. More specifically, he highlights four heroic poems, ranging from the middle of the fourteenth to the second half of the sixteenth century, and holds that the different representations of this mythical figure reflect the varying contexts of these works.

In the final contribution, Andrea Polegato constructs the play II Marescalco (the Stablemaster) by Pietro Aretino (1492-1556) as a window into the inner workings of the relationship between a ruler and his court.

This thematic issue ends with the customary translation section, a number of book reviews and a series of announcements from or relevant to the scholarly community in Flanders and the Netherlands.

\section{David Napolitano}

University of Cambridge

Trinity Hall - Wychfield Site, Storey's Way

CB3 ODZ Cambridge (UK)

dphn2@cam.ac.uk 